\title{
The intraday effects of central bank intervention on exchange rate spreads
}

Fatum, Rasmus; Pedersen, Jesper; Sørensen, Peter Norman

Published in:

Journal of International Money and Finance

DOI:

10.1016/j.jimonfin.2012.10.006

Publication date:

2013

Document version

Early version, also known as pre-print

Citation for published version (APA):

Fatum, R., Pedersen, J., \& Sørensen, P. N. (2013). The intraday effects of central bank intervention on exchange rate spreads. Journal of International Money and Finance, 33, 103-117.

https://doi.org/10.1016/j.jimonfin.2012.10.006 


\section{The Intraday Effects of Central Bank Intervention on Exchange Rate Spreads}

June 28, 2012

Rasmus Fatum*

School of Business

University of Alberta

Edmonton, Alberta

Canada, T6G 2R6

Email: rasmus.fatum@ualberta.ca
Jesper Pedersen

Danmarks Nationalbank

Havnegade 5

DK-1093 Copenhagen K

Denmark

Email: jep@ nationalbanken.dk

Peter Norman Sørensen

Department of Economics

University of Copenhagen

Øster Farimagsgade 5, Building 26

DK-1353 Copenhagen K

Denmark

Email: peter.norman.sorensen@econ.ku.dk

Abstract: We investigate the intraday effects of intra-marginal intervention in a horizontal band on the exchange rate spread. Official intraday data on Danish intervention transactions in the ERM II, the Exchange Rate Mechanism of the European Union, facilitates our analysis. We show that intervention purchases and sales both exert a significant influence on the exchange rate spread, but in opposite directions. Intervention purchases of the small currency, on average, narrow the spread while intervention sales of the small currency, on average, widen the spread. This is a novel finding that differs from those of existing studies that find intervention always widens the exchange rate spread and increases market uncertainty.

Key words: Foreign Exchange Intervention; ERM II; Exchange Rate Spreads; Intraday Data

JEL Classifications: E58; F31; G15

* Corresponding author. Fatum and Sørensen gratefully acknowledge financial support from the Social Sciences and Humanities Research Council of Canada (SSHRC) and the Danish Social Science Research Council, respectively. We thank an anonymous referee as well as seminar participants at Danmarks Nationalbank, the Federal Reserve Bank of Dallas, and the University of Copenhagen for very helpful comments. We also thank Danmarks Nationalbank for providing the official intraday intervention data. The views expressed do not necessarily reflect the views of Danmarks Nationalbank. 
Many studies have investigated the intraday effects of foreign exchange intervention. ${ }^{1}$

Few studies have examined the intraday effects of intervention using accurate, official intraday intervention data. ${ }^{2}$ Even fewer studies have analyzed the intraday effects of intervention on exchange rate spreads. These studies examine the spread effects of intervention in a crawling peg (Melvin, Menkhoff and Schmeling 2009) and the spread effects of intervention in floating exchange rates (Chari 2007 and Pasquariello 2007). ${ }^{3}$ All of these studies find that foreign exchange intervention is associated with an intraday increase in the bid-ask exchange rate spread.

In this paper we investigate how unannounced intra-marginal intervention in a horizontal band such as the ERM II, the Exchange Rate Mechanism of the European Union, influences the bid-ask exchange rate spread. Official intraday data on intervention transactions in the Danish Krone-Euro (DKK/EUR) market provided by Danmarks Nationalbank (DN), the Danish central bank, facilitates our analysis. ${ }^{4}$

\footnotetext{
${ }^{1}$ See Humpage (2003), Menkhoff (2010), Neely (2005) and Sarno and Taylor (2001) for surveys of the intervention literature.

${ }^{2}$ The Bank of Canada, Danmarks Nationalbank, and the Swiss National Bank are the only central banks to provide access to lengthy records of time-stamped intervention data. Records of time-stamped interventions (spanning 1986 to 1995) by the Swiss National Bank are the only publicly available intraday intervention data. See Fischer and Zurlinden (1999) for an early contribution that uses official Swiss intraday intervention data to analyze the effects of announced intervention on the level of the exchange rate. See Fatum and King (2005) for a study of the intraday effects of Canadian interventions.

${ }^{3}$ Melvin, Menkhoff and Schmeling (2009) present a case study of 5 days of intervention by the Russian Central Bank. Chari (2007) uses newswire reports in lieu of actual Bank of Japan intraday intervention data and analyzes a period of roughly one year. Pasquariello (2007) analyzes 9 years of official Swiss intraday intervention data.

${ }^{4}$ In ERM II, a bilateral central rate and a horizontal deviation band is set for the currency of the participating country vis-à-vis the EUR, but not against the currency of other member states. Only if the currency reaches either the upper or the lower limit of the deviation band is the European Central Bank (ECB) obligated to intervene. The official ERM II deviation band for the DKK is +/- 2.25 percent around the official Danish ERM II central rate of 7.46038 DKK/EUR. During the period under study the DKK traded within a narrower range and was consistently appreciated relative to the official central rate. All interventions in the DKK/EUR rate have been carried out unilaterally by the DN. See DN (2003), ECB (2004), and Fatum and Pedersen (2009) for details on ERM II and the Danish exchange rate policy.
} 
It is interesting to investigate how the exchange rate spread is influenced by intervention since doing so can reveal if intervention increases or reduces foreign exchange market uncertainty regarding whether a currency is seen as properly priced. ${ }^{5}$ It is particularly interesting to analyze the effects of intervention on exchange rate spreads using the Danish intervention data for three reasons. First, the Danish intervention data presents a very rare opportunity for learning about the influence of intervention on exchange rate spreads using official, time-stamped data provided by a currently intervening central bank. ${ }^{6}$ Second, no previous study has analyzed the effects of intervention in a horizontal band, such as the ERM II band, on exchange rate spreads. Third, analyzing the Danish experience of intra-marginal interventions in the horizontal ERM II band can bring insights of relevance to Denmark and to other EU member states currently participating in the ERM II as well as to the EU member states that are not in the Euro-zone and are not participating in the ERM II, but are expected to participate in ERM II at a later date in order to fulfill the exchange rate criterion necessary for adopting the EUR. ${ }^{7}$

In our context of unannounced intervention by a small central bank aimed at maintaining a small currency in a horizontal band around a major currency, such as maintaining the DKK against the EUR in the ERM II, we cannot assume that the effects of intervention purchases and sales are necessarily symmetric and that foreign exchange

\footnotetext{
${ }^{5}$ Empirical evidence shows that bid-ask spreads widen when uncertainty increases. See, for example, Bollerslev and Melvin (1994). See Chari (2007) for a useful discussion of intervention and exchange rate spreads in a microstructure context.

${ }^{6}$ Hitherto Danish intraday intervention data has only been analyzed by Fatum and Pedersen (2009) who study the intraday effects of intervention on the exchange rate level; they do not consider the influence of intervention on the exchange rate spread.

${ }^{7}$ Denmark, Latvia and Lithuania are currently in ERM II. Bulgaria, The Czech Republic, Hungary, Poland, Romania, Sweden, and the United Kingdom have not adopted the EUR and do not participate in ERM II. Denmark and the United Kingdom are the only EU member states with a formal exemption clause ("optout") according to which adoption of the EUR is not obliged.
} 
intervention is always associated with an intraday increase in the bid-ask exchange rate spread. ${ }^{8}$ First, it is reasonable to assume that as the intervention occurs, foreign exchange market customers observe only a large order flow but cannot discern the origin of the trade. ${ }^{9}$ Therefore, an unannounced intervention by the small central bank, whether a sale or a purchase, is initially understood by customers only as a large trade and, accordingly, interpreted as informative regarding pressure, either upwards or downwards, on the small currency. An unannounced intervention by the small central bank, however, is unlikely to be interpreted as informative regarding pressure on the large currency. ${ }^{10}$

Second, downward pressure on a currency in a horizontal band is potentially more concerning than upward pressure, especially if the downward pressure adversely affects the credibility of the currency and its exchange rate regime. ${ }^{11}$ This concern is particularly relevant for the DKK, which has a relatively recent history of instability and frequent devaluations prior to participation in the ERM I, the predecessor of the ERM II. The fact

\footnotetext{
${ }^{8}$ The empirical intervention literature in general pays limited attention to the possibility that the effects of intervention might be asymmetric across intervention purchases and intervention sales. Oftentimes estimated models implicitly and a priori impose symmetry across purchases and sales by simply not distinguishing between the two, or by analyzing data sets encompassing only interventions in one direction. For example, of the aforementioned three existing studies of the intraday effects of intervention on the exchange rate spread, only Pasquariello (2007) analyzes intervention data encompassing both intervention purchases and intervention sales.

${ }^{9}$ The dealers, i.e. the commercial bank counterparts to the $\mathrm{DN}$, are explicitly requested not to disseminate information regarding the origin of the DN initiated intervention trades to their customers. See Bhattacharya and Weller (1997), Ghosh (2002), and others for the advantages of unannounced interventions.

${ }^{10}$ A large sale of the small currency by the small central bank against the large currency might indicate that the small currency is overvalued and subject to downward pressure, possibly leading to uncertainty regarding the sustainability of the exchange rate regime. By contrast, a large purchase of the large currency by the small central bank against the small currency would not necessarily imply that there is upward pressure on the large currency since there are plenty of currencies other than this particular small currency against which pressure on the large currency can be levied.

${ }^{11}$ Intervention purchases of the domestic currency are, in principle, restricted by the amount of finite foreign exchange reserves at the disposal of the small country, whereas intervention sales are, in principle, unrestricted as the monetary authority of the small country has the capability to print money to sell against the large currency. However, the ECB is obligated to intervene if an ERM II currency reaches a deviation band limit, thereby effectively lifting the finite amount restriction of foreign exchange reserves held by the ERM II member state.
} 
that the DKK is continuously maintained at an appreciated rate relative to the central rate corroborates that downward pressure is viewed as more concerning than upward pressure. Reduced credibility will manifest itself in the form of increased uncertainty and thus a widening of the exchange rate spread. By contrast, a large purchase of the small currency may be interpreted as a confirmation of the credibility of the small currency and the exchange rate regime, thereby leading to reduced uncertainty and thus a narrowing of the exchange rate spread. In other words, the effects of unannounced intervention in a horizontal band could be asymmetric across purchases and sales.

To assess the intraday effects of intervention on the exchange rate spread in the horizontal ERM II band, and to formally test whether intervention purchases and intervention sales influence the spread asymmetrically, we estimate time-series models of the DKK/EUR exchange rate bid-ask spread, calculated from indicative 5-minute spot bid and ask DKK/EUR prices purchased from Olsen and Associates, with intervention purchases and sales entering as separate explanatory variables. Our sample covers the 1 August 2002 to 31 December 2004 period. We carry out our baseline estimations using OLS with heteroskedasticity and autocorrelation consistent (HAC) standard errors and covariances. As a methodological robustness test we also estimate models using the weighted least squares (WLS) procedure developed by Andersen and Bollerslev (1998).

Consistent with the existing studies of the intraday effects of intervention on the exchange rate spread in the context of a crawling peg or floating exchange rates, our results confirm that intervention significantly influences the spread. However, in contrast with these studies, we show that interventions in a horizontal band do not necessarily increase the spread. Instead, we show that intervention purchases of the small currency, 
on average, reduce the spread, while only intervention sales, on average, increase the spread. This finding conforms to the suggestion that uncertainty in the market regarding the exchange rate decreases when interventions can be interpreted as upward pressure on the small currency, while uncertainty in the market increases when interventions can be interpreted as downward pressure on the small currency. Our results hold up against an array of robustness checks, including employing a different econometric procedure and controlling for coincidental arrival of macro news.

The rest of the paper is organized as follows. Section 2 briefly outlines the traditional intervention transmission channels and their relevance to the Danish interventions. Sections 3 and 4 present the data and the empirical model, respectively. Section 5 discusses the results. Section 6 presents several robustness checks. Section 7 concludes.

\section{Transmission Channels and Danish Interventions}

The intervention literature has identified the signaling channel, the coordination channel, the portfolio balance channel, and the noise-trading channel as possible transmission channels through which sterilized intervention might work. This section briefly outlines key elements of each of these four traditional intervention transmission channels and their relevance in the particular context of the DN interventions. ${ }^{12}$

The idea of the signaling channel hypothesis is that by carrying out intervention the central bank informs the market, or sends a signal, about its future monetary policy intentions. Assuming that financial markets are forward-looking and monetary policy is a

\footnotetext{
${ }^{12}$ For detailed discussions of the transmission channels see Mussa (1981) regarding the signaling channel, Edison (1993) regarding the signaling and the portfolio-balance channels, Sarno and Taylor (2001) regarding the coordination channel, and Hung (1997) regarding the noise-trading channel.
} 
foreign exchange rate determinant, information about future monetary policy can then influence current exchange rates. In order for intervention to send a signal, and thus for the functioning of the signaling channel, intervention must be announced or detected by the market (where market detection implies that an intervention is indeed understood to be an intervention carried out by the central bank rather than incorrectly perceived as a privately initiated trade).

The coordination channel pertains to a situation of substantial exchange rate misalignment and coordination failure to the extent that individual market participants are hesitant to risk betting on a reversal of the exchange rate towards its equilibrium. In such a situation the coordination channel proposes that announced or detected intervention can take on a coordinating role that organizes fundamentalist traders to enter the market at the same time, thereby causing the exchange rate to adjust. In order for intervention to send a coordinating signal, and thus for the functioning of the coordination channel, intervention must be announced or detected by the market.

The portfolio balance channel relies on foreign and domestic assets (bonds) being imperfect substitutes. The intervention changes the relative supplies of these assets and leads to a market-clearing change in relative asset returns in order for investors to demand both foreign and domestic assets. The portfolio balance channel then suggests that the change in relative asset returns, in the absence of changes in relative nominal interest rates, is generated by an adjustment of the current exchange rate.

According to the noise-trading channel monetary authorities intervening against strong exchange rate momentum must intervene secretly to achieve an increase in shortterm exchange rate volatility in order to manipulate non-fundamentalist traders (i.e. 
noise-traders, or chartists) to second-guess the strength and duration of the (from the perspective of the monetary authorities) undesirable exchange rate trend. Consequently, in order for intervention to work through the noise-trading channel, intervention must be unannounced as well as undetected.

As noted earlier, the DN interventions are unannounced and, as discussed in the next section, rarely reported in the newswire services. Therefore, it seems improbable that the DN interventions would influence the DKK/EUR through either the signaling or the coordination channels, i.e. the two channels that rely on market awareness in order for intervention to be influential. There is no similar reason to dismiss the possibility that the DN interventions are effective through the portfolio-balance channel (the portfoliobalance channel does not require interventions to be announced or detected in order to function). However, this channel does not consider the effects of intervention on market uncertainty, and it does not explain the possibility of asymmetric effects of intervention. In our context of investigating the effects of intervention on the exchange rate spread, and whether these effects are asymmetric across intervention purchases and sales, the portfolio-balance channel, therefore, is of limited interest. By contrast, the noise-trading channel, which pertains only to secret interventions, i.e. interventions that are both unannounced and undetected, seems particularly relevant in our context. Although the noise-trading channel suggests that secret interventions work by increasing exchange rate volatility and does not explicitly consider the possible influence of intervention on exchange rate spreads, it seems reasonable to equate exchange rate volatility and exchange rate spreads in the sense that both can be interpreted as measures of market uncertainty. In doing so it is clear that the DN interventions must necessarily increase the 
bid-ask DKK/EUR spread in order for any effects of the DN interventions on the value of the DKK to be consistent with the transmission mechanism described by the noisetrading channel. We discuss our empirical findings in light of the noise-trading channel at the end of Section 5.

\section{Data}

The intervention data covers all DN interventions in the DKK/EUR market over the 1 August 2002 to 31 December 2004 period. ${ }^{13}$ The data includes the exact amount and time-stamp to the nearest minute obtained directly from the trade-sheet of each intervention transaction. Intervention amounts are quoted in EUR and a positive amount denotes a purchase of EUR against a sale of DKK. ${ }^{14}$

Table 1A displays descriptive statistics of the intervention data, and Figure 1 shows the interventions juxtaposed against the DKK/EUR exchange rate. Our sample consists of a total of 73 intervention days, encompassing a total of 162 intervention transactions. On intervention days, the average daily intervention amount is EUR 155 million, which is roughly $8 \%$ of the average daily turnover in the DKK/EUR market. ${ }^{15}$

\footnotetext{
${ }^{13}$ The sample period is determined by data availability.

${ }^{14}$ In accordance with the ERM II provisions, the DN trader conducting an intervention operation is required to write the amount and the exact time of the operation on the trade-sheet immediately after the completion of each individual intervention transaction. This information is forwarded to the ECB by the end of the trading day, at the latest. Our intraday intervention data consists of this extremely reliable information.

${ }^{15}$ Average daily turnover in the DKK/EUR market was USD 2,236 million in 2004, or roughly EUR 1,900 million when converted at the prevailing USD/EUR rate of 1.2. See BIS Triennial Central Bank Survey of Foreign Exchange and Derivatives Market Activity in 2004, http://www.bis.org/publ/rpfxf07t.htm Statistical Annex Table E.6, pp 61, for statistics on average daily turnover in the DKK/EUR market.
} 
The DN follows standard central bank practice in not announcing its interventions. Furthermore, the DN interventions are rarely reported in the newswire services and none of the reports mentions amount or timing of the interventions. ${ }^{16}$

The high-frequency DKK/EUR exchange rate data is provided by Olsen and Associates. The data consists of the bid and the offer spot exchange rate at the end of every 5-minute interval over every 24 -hour period. The quotes are indicative quotes, i.e. not necessarily traded quotes. We follow Dacorogna, Müller, Nagler, Olsen and Pictet (1993) and filter the data for anomalies and bad quotes. ${ }^{17}$ Table $1 \mathrm{~B}$ summarizes key statistical properties of our 5-minute bid-ask exchange rate spreads (defined as ask minus bid). Figure 2 shows the average intraday spread across the intervals of the day.

There is virtually no trading of the Danish currency outside of standard Danish business hours (see DN 2003 and ECB 2004), thus we define a trading day in the Danish currency market to start at $8.00 \mathrm{GMT}+1$ and finish at $17.00 \mathrm{GMT}+1 .{ }^{18}$ Consequently, our analysis considers a total of 603 trading days consisting of a total of 64383 5-minute DKK/EUR exchange rate bid-ask spreads. ${ }^{19}$ Importantly, our trading day definition encompasses all intervention transactions during the period under study.

\footnotetext{
${ }^{16}$ A Factiva search for both English and Danish language newswire reports of DN interventions over the August 2002 to December 2004 period, using various search word combinations such as "Danish intervention", "Danmarks Nationalbank", and "Danish Crown" etc., finds only four intervention reports in total (three English language reports from Reuters News and one Danish language report from a Danish daily newspaper). The reports are available upon request.

${ }^{17}$ Superior transactions bid and ask prices are not available for the DKK/EUR exchange rate market for the period under study. For this reason we refrain from assessing the economic significance implied by the coefficient estimates when discussing the estimation results in Section 5. See Danielsson and Payne (2002) for a detailed comparison of indicative quotes to transactions data.

${ }^{18}$ This definition of a trading day carries over naturally to a definition of a weekend, i.e. we define a weekend to start at 17.05 GMT+1 Friday and finish at 8.00 GMT+1 Monday.

${ }^{19}$ We also deleted the following holidays from the analysis: 1 January, Easter (three holidays), Christmas (24/25/26 December), 31 December as well as four Denmark-specific holidays (Store Bededag, Kristi Himmelfartsdag, Anden Pinsedag, and Grundlovsdag).
} 
Danish and Euro-Area interest rates are obtained from the websites of DN (www.nationalbanken.dk) and the ECB (www.ecb.int), respectively. Time-stamped Danish, German, and Euro-area macro announcements and preceding survey expectations are obtained from Bloomberg. Summary statistics regarding interest rates and macro news are available from the authors upon request.

\section{The Empirical Model}

We follow Melvin, Menkhoff and Schmeling (2009) and use OLS with heteroskedasticity- and serial-correlation consistent (HAC) errors to model the exchange rate spread, $\mathrm{SP}_{t}$, as a linear function of (absolute) intervention, $\mathrm{I}_{t}$, and lagged values of the spread itself:

$$
S P_{t}=\beta_{0}+\sum_{j=1}^{J} \beta_{j} S P_{t-j}+\gamma_{0}\left|I_{t}\right|+\varepsilon_{t}, t=1 \ldots T
$$

As noted earlier, $\mathrm{T}=64383$. We choose $\mathrm{J}=6$ based on the Schwartz and Akaike information criteria. We test for delayed effects of intervention and control for macro news in the robustness section.

This preliminary specification ignores the possibility of asymmetric effects across (absolute) intervention purchases, $\left(\mathrm{I}_{\mathrm{t}}^{\mathrm{P}}\right)$, and (absolute) intervention sales, $\left(\mathrm{I}_{\mathrm{t}}^{\mathrm{S}}\right)$. To allow for the possibility of asymmetries we estimate the following model:

$$
S P_{t}=\beta_{0}+\sum_{j=1}^{J} \beta_{j} S P_{t-j}+\gamma^{P}{ }_{0}\left|I^{P}{ }_{t}\right|+\gamma^{S}{ }_{0}\left|I^{S}{ }_{t}\right|+\varepsilon_{t}, t=1 \ldots T
$$

We include as additional explanatory variables the distance from parity, i.e. a measure of the distance between the DKK/EUR exchange rate and the central rate, the EUR-DKK interest rate differential, as well as lags (two and six, respectively) of the 5- 
minute exchange rate volatility. We use the absolute value of the residual of the conditional mean model of the exchange rate return, as estimated in Fatum and Pedersen (2009), as a proxy for the 5-minute exchange rate volatility. ${ }^{20}$

The distance from parity and the interest rate differential variables are insignificant. $^{21}$ The inclusion of lags of volatility improves the overall fit of the model, but the significance level and size of the coefficient estimates of the lags of the spread are affected by this inclusion (due to multicollinearity between spread and volatility). The results with respect to significance of the intervention variables are unchanged regardless of whether or not lags of volatility are included in the estimations. As a result, we exclude these additional explanatory variables from the rest of the analysis. Results with the additional variables included are available from the authors upon request.

\section{Results}

The first column of Table 2 displays the results of the OLS-HAC estimation of Equation

1. As the table shows, the coefficient estimate associated with intervention is insignificant, i.e. we find no evidence that intervention, on average, has an intraday influence on the exchange rate spread. Clearly, this seems at odds with the existing intraday studies of intervention and spreads who all find that foreign exchange intervention is associated with an intraday increase in the bid-ask exchange rate spread

\footnotetext{
${ }^{20}$ The results of the daily data analysis of intervention in ERM I by Brandner, Grech and Stix (2006) show that the distance from parity significantly influences the level of the DKK/DEM exchange rate. In the context of intraday data and intervention in ERM II, Fatum and Pedersen (2009) find no significant effects of either distance from parity or the EUR-DKK interest rate differential on the level of the DKK/DEM exchange rate. The intraday analysis of intervention and spreads by Melvin, Menkhoff and Schmeling (2009) includes two lags of both spread and volatility in some of their estimations. Their results in regards to intervention are not affected regardless of whether lags of spreads and volatility are included.

${ }^{21}$ When we consider the distance from the DKK/EUR rate to the sample mean of the DKK/EUR rate we find evidence that the further away from the sample mean the larger is the bid-ask spread. Inclusion of this alternative distance measure does not influence the results with respect to the intervention variables.
} 
(see Chari 2007; Melvin, Menkhoff and Schmeling, 2009; and Pasquariello 2007). ${ }^{22} \mathrm{We}$ discuss our findings and why they might differ from those of the existing literature after presenting the results of the analysis that allows for the possibility asymmetric effects across intervention purchases and sales.

To test for such intervention asymmetries we estimate the baseline model with intervention purchases and sales entering as separate variables (as described in Equation 2). The results, displayed in the second column of Table 2, show that contemporaneous intervention purchases of DKK as well as contemporaneous intervention sales of DKK are significant (at $95 \%$ and $90 \%$, respectively) but influence the exchange rate spread in opposite directions. Specifically, intervention purchases of the small currency decrease the exchange rate spread while intervention sales of the small currency increase the spread.

Certainly, these results make clear the necessity of distinguishing between intervention purchases and intervention sales when assessing the influence of intervention on exchange rate spreads, at least in our context of unannounced intervention in a horizontal band. Moreover, the results corroborate the idea that unannounced interventions, of which the foreign exchange market customers cannot know the origin and, therefore, observe only as large order flows, affect the perception of the market regarding whether there is pressure on a currency and in which direction. The interpretation of a large sale of the small currency as an indication of the relatively more

\footnotetext{
${ }^{22}$ The lack of significance of intervention, on average, is also at odds with Naranjo and Nimalendran (2000) who, in the context of intervention in the DEM/USD market over the 1976 to 1994 period, find that intervention, on average, increases the spread. Their analysis, however, pertains to daily data on intervention in a floating exchange rate over an 18 year period during which intervention occurs on almost a third of the trading days in their sample (intervention occurs on 1512 of their 4723 trading days under study). Therefore, their data and context are substantially different from ours thus it does not seem meaningful to further compare our findings to theirs.
} 
concerning downward pressure within the horizontal band increases market uncertainty and widens the spread. By contrast, the interpretation of a large purchase of the small currency as an indication of upward pressure is a confirmation of the exchange rate regime in the sense that the lower bound is less likely to be tested and, as a result, market uncertainty decreases and the spread narrows.

Since no previous study has investigated the influence of intervention on exchange rate spreads in the context of the horizontal ERM II band, we compare our findings to existing studies of intervention and spreads with caution. That said, it is nevertheless interesting to note that our results are, upon closer inspection, consistent with the findings of both Chari (2007) and Melvin, Menkhoff and Schmeling (2009). Their samples consist of only intervention sales (intervention sales of JPY and RUB, respectively, against USD), thus by nature of their intervention data they do not consider the influence of intervention purchases. They find that intervention sales of the smaller currency increase the spread, as do we. This could suggest that the downward pressure concern manifests itself not only in our context of the horizontal ERM II band, but also in other exchange rate systems such as floating rates. More research, such as analyzing the intraday effects of intervention purchases of JPY, is warranted in order to answer whether intervention asymmetries are present in, say, floating rates.

Unlike the intervention data studied by Chari (2007) and Melvin, Menkhoff and Schmeling (2009), the Swiss intraday intervention data investigated by Pasquariello (2007) contains both purchases and sales. Contrary to the insignificant intervention coefficient of our preliminary analysis that does not distinguish between purchases and sales, he finds that intervention, on average, increases the intraday spread. However, 
Pasquariello (2007) also shows that intervention sales of the CHF exert a stronger influence on the CHF/USD spread than intervention purchases of the CHF. Our results, therefore, are consistent with his in terms of intervention sales of the smaller currency increasing the spread and in terms of showing that the effects on the spread of intervention purchases and sales are asymmetric. By contrast, our results differ in regards to whether intervention purchases of the small currency decrease the spread, as in our data, or whether intervention purchases merely increase the spread less than intervention sales, as in Pasquariello (2007). We conjecture that this difference is due to the fact that our context is that of unannounced intervention in a horizontal band while the Swiss interventions are announced and carried out in a floating exchange rate regime. Only in our context can a purchase of the small currency be interpreted by the market as a confirmation of the credibility of the band which, as we suggest, is the reason why intervention purchases reduce market uncertainty and narrow the spread. ${ }^{23}$

Lastly, it is also particularly interesting to relate our findings to those of Fatum and Pedersen (2009) since doing so allows us to assess whether the effects of the DN interventions are consistent with the noise-trading channel. Fatum and Pedersen (2009) find that intervention sales of DKK significantly depreciate the DKK while intervention purchases of DKK have no detectable effect on the level of the DKK/EUR rate. Our findings in conjunction with those of Fatum and Pedersen (2009) thus suggest that interventions that cause the spread to widen also induce a significant adjustment of the DKK/EUR exchange rate level, whereas interventions that cause the spread to narrow do not. As noted earlier, in order for intervention to be effective in influencing relative

\footnotetext{
${ }^{23}$ The CHF is a widely traded safe-haven currency while the DKK is not. We therefore compare the details of our findings to those of Pasquariello (2007) with particular caution.
} 
currency values through the noise-trading channel, intervention must be associated with an increase in market uncertainty. Although not a formal validation of the noise-trading channel, our findings in conjunction with those of Fatum and Pedersen (2009) are clearly consistent with the transmission mechanism described by the noise-trading channel.

\section{Robustness}

In order to test the robustness of our results we model the intraday periodicity of the bidask spread, re-estimate the baseline model using a different econometric procedure, take into account the possibility that the intervention variables contain expected components, control for macro news surprises, include lags and leads of the intervention variables, test for structural breaks, and consider the position as well as the short-term trend of the exchange rate at the time of intervention. Results pertaining to intraday periodicity, delayed effects, lead effects, break point test, the exchange rate position and trend are not shown for brevity but available from the authors upon request.

First, to ensure that our intervention coefficient estimates are not biased from ignoring the possibility of intraday periodicity in the bid-ask spread, we re-estimate the conditional mean models described in Equations (1) and (2) with a Flexible Fourier Form included (see Gallant 1981). While the results indicate that intraday periodicity is present in the spread, the baseline results regarding the intraday influence of intervention on the spread are unaffected by the inclusion of the Flexible Fourier Form.

Second, we re-estimate the models described in Equations (1) and (2) using the weighted least squares (WLS) procedure developed by Andersen and Bollerslev (1998). The results of the conditional mean estimations, displayed in Table 3 (the first column 
shows the results of the preliminary estimation that does not allow for asymmetries and the second column shows the results using separate intervention purchases and sales variables), are virtually identical to those of the OLS-HAC estimations. The intervention variable described in Equation (1) is, again, insignificant while both intervention variables (purchases and sales) described in Equation (2) are, again, significant and of opposite signs. The only difference is that the WLS estimation results are marginally stronger in the sense that both intervention sales and intervention purchases are now significant at the $95 \%$ level compared to the OLS-HAC estimations (Table 2) where intervention sales are significant at $95 \%$ and intervention purchases are significant at only $90 \%$.

Third, while there is no reason to believe that intervention is triggered by the contemporaneous exchange rate spread (i.e. the change in the exchange rate spread that occurs over the 5-minute interval within which intervention is carried out), intervention is nevertheless correlated with recent (lagged) exchange rate movements and with recent (lagged) intervention, even at the intraday frequency. ${ }^{24}$ We follow Humpage (1999) and others by estimating a central bank reaction function and, in turn, use the residuals of the reaction function to replace the actual intervention variable in our empirical models of the exchange rate spread. This procedure ensures that any component of intervention that is easily predictable, i.e. captured by the reaction function estimation, is not leading to a bias of the estimated effects on the exchange rate spread. The results of estimating the effects of the reaction function generated intervention variable on the spread are displayed in Table 4 (the first column shows the results when all interventions are contained in one variable while the second column shows the results using separate

\footnotetext{
${ }^{24}$ See Neely $(2001,2008)$ for useful insights on what prompts central bank intervention.
} 
intervention sales and purchases variables). As the table shows, the results are qualitatively identical to the comparable results from estimations that do not employ the intervention variable generated from the residuals of the intervention reaction function. ${ }^{25}$

Fourth, to ensure that our estimated effects of intervention are not tainted by the coincidental arrival of macro news, we extend our analysis to include time-stamped Danish, German, and Euro-area macro surprises. This is important because macro surprises can change the perception of the market in regards to whether a currency is properly aligned with fundamentals, i.e. we need to make sure that what we label the reaction of the market to unannounced interventions is not in actuality a matter of the market adjusting to unexpected macro news. To address this concern we include macro surprises regarding Danish Unemployment (DKUNEMP), Trade Balance (DKTB), Current Account (DKCA), CPI (DKCPI), GDP (DKGDP) and Consumer Confidence (DKCC); German IFO Index (DEIFO), GDP (DEGDP), and Industrial Production (DEIP); Euro-Area CPI (EACPI), Industrial Production (EAIP), and Business Climate Index (EABC). Macro surprises are measured as the difference between macro announcement and preceding survey expectation. To facilitate a comparison of the relative influence of macro news and interventions, all macro and intervention variables are standardized (i.e. we divide each variable by its sample standard deviation). The results of the estimations with macro surprises included, displayed in Table 5, show that

\footnotetext{
${ }^{25}$ The daily data literature on central bank reaction functions generally obtains a reasonable goodness of fit (see, for example, Ito and Yabu 2007 who model daily interventions carried out by the Japanese authorities). However, in our context of modeling the Danish interventions at the intraday frequency we are unable to achieve a reaction function $\mathrm{R}^{2}$ above $1 \%$. The low goodness of fit suggests that the intraday timing of the Danish interventions is largely unpredictable and, consequently, that the actual intervention variable and the intervention variable generated from the residuals of the intervention reaction function estimation are very similar. It is therefore unsurprising that replacing the actual intervention variable in the baseline model with the reaction function residuals yields identical results.
} 
some of the macro surprises influence the spread. More importantly, the results regarding the asymmetric effects of intervention purchases and sales remain. ${ }^{26}$

Fifth, in order to test for delayed effects of intervention, we re-estimate our models described in Equations 1 and 2 with 12 lags (60 minutes) of both intervention purchases and intervention sales included. The results show no systematic pattern of delayed effects and the cumulative sums of lags are all insignificant. Moreover, the previously discussed asymmetric contemporaneous effects of intervention purchases and sales, respectively, are unchanged.

Sixth, we address the possibility that the market anticipates and, therefore, reacts in advance of the interventions by testing for the presence of lead effects. Specifically, we add two (10 minutes) and, subsequently, six leads (30 minutes) of intervention purchases and intervention sales to the models in Equations 1 and 2. None of the leads is individually significant and, moreover, the respective sums of leads (two or six leads) are not significantly different from zero.

Seventh, to ensure that our parameter estimates are valid across the entire sample period we employ the Andrews (1993) test for unknown break point. The test does not detect any evidence of a break point and, therefore, we accept the hypothesis of parameter stability across our sample. ${ }^{27}$

\footnotetext{
${ }^{26}$ Interestingly, the relative influence of intervention is generally quite small compared to the relative influence of macro news. This is, however, not surprising considering that, as previously discussed, the Danish interventions are carried out to confirm the commitment of the Danish exchange rate policy rather than to calm disorderly markets, or to bring about substantial changes in the DKK/EUR exchange rate.

${ }^{27}$ The institutional framework of the ERM II stipulates that the European Central Bank is obligated to intervene if the ERM II currency reaches either the upper or the lower limit of the deviation band. An increase in currency reserves held by the ERM II central bank should, therefore, not necessarily influence the credibility of the ERM II target zone or how intervention affects the exchange rate market. It is thus not surprising that the Andrews (1993) test for structural break rejects the presence of a break despite the fact that the stock of Danish foreign currency reserves more than doubled from 2002 to 2004.
} 
Eighth, we test whether interventions that occur when the DKK/EUR rate is relatively far away from its sample mean are more (or less) influential by adding to the baseline model two interactive dummy variables that equal $\left|\mathrm{I}_{\mathrm{t}}^{\mathrm{P}}\right|$ and $\left|\mathrm{I}_{\mathrm{t}}^{\mathrm{S}}\right|$, respectively, when either $\mathrm{I}_{t}^{\mathrm{P}}$ and $\mathrm{I}_{t}^{\mathrm{S}}$, respectively, occur when the DKK/EUR rate is at least two standard deviations away from its sample mean. Our results suggest that intervention sales of DKK increase the spread and intervention purchases of DKK decrease the spread (our baseline result) and that these effects are more pronounced if the interventions occur at a time when the exchange rate is relatively far away from its sample mean.

Ninth and final, to consider the possibility that the preceding short-term exchange rate movement is a factor in determining the extent to which interventions are influential we first define leaning with the wind interventions as interventions carried out in the same direction as the immediately preceding 1-hour exchange rate trend. We then add to the baseline model two interactive dummy variables ("slope-shifters") that take on the value of $\left|\mathrm{I}_{\mathrm{t}}^{\mathrm{P}}\right|$ and $\left|\mathrm{I}_{\mathrm{t}}^{\mathrm{S}}\right|$, respectively, when leaning with the wind intervention purchases and sales occur (and zero otherwise). The results of estimating the augmented model confirm the findings regarding the asymmetric effects on the exchange rate spread across intervention purchases and intervention sales. The results also show that both slopeshifters are insignificant. These findings are repeated when we define leaning with the wind interventions according to the immediately preceding 9-hour (the duration of a business day) exchange rate movement. Accordingly, we find no evidence that the immediately preceding short-term exchange rate movement is a factor in determining the extent to which interventions are influential. 


\section{Conclusion}

The existing literature on intervention and spreads is very scarce, and it does not consider intervention in a horizontal band such as the ERM II. Our study is the first to analyze the intraday effects of intra-marginal intervention on the exchange rate spread in the context of a horizontal ERM II band. Proprietary data on official Danish intervention transactions in the DKK/EUR exchange rate market facilitates our analysis.

It is interesting to investigate how the exchange rate spread is influenced by intervention because doing so can reveal whether intervention affects foreign exchange market uncertainty. It is particularly interesting to study the Danish intervention experience in ERM II since it can provide valuable insights of relevance to not only Denmark but also to the currently 8 EU member states that have not yet adopted the EUR but are legally required to do so at some point in time. These $8 \mathrm{EU}$ member states, therefore, are either already participating in the ERM II or expected to participate in the ERM II at a later date prior to joining the Euro-area.

Our time-series estimations of the 5-minute DKK/EUR exchange rate bid-ask spread provide two insights. First, we show that failure to allow for the possibility of asymmetric affects across intervention purchases and intervention sales can lead to failure to detect the influence of intervention. This is a result of general interest as it illustrates the necessity of considering asymmetries when assessing the influence of large trades, such as intervention transactions, in foreign exchange rate markets.

Second, we show that intervention purchases and sales in a horizontal ERM II band both significantly influence the spread, but the direction of the intervention matters for the resolution, or creation, of uncertainty in the market. Specifically, we show that 
intervention purchases of the ERM II currency, on average, reduce the spread while intervention sales of the ERM II currency, on average, increase the spread.

This is a new and interesting result that differs from those of existing studies that find intervention to increase market uncertainty regardless of the direction of the intervention. It is also a finding of practical relevance to authorities with the mandate to carry out interventions in the context of a horizontal band. Contrary to findings of studies analyzing intervention in floating exchange rates that, regardless of the exchange rate level or volatility effects of intervention, show that intervention is costly because it increases market uncertainty, we show that this is not necessarily the case. Instead, depending on the direction of intervention, we show that intervention can, in fact, reduce market uncertainty. Lastly, our result has implications for hedge funds and other speculators that may profit when spreads widen or narrow with intervention in a predictable manner.

The institutional framework surrounding intervention in a horizontal ERM II band is markedly different from that of intervention in other exchange rate regimes such as, for example, floating rates. Therefore, we can not infer that our results describe the intraday effects of intervention on the exchange rate spread in general, i.e. regardless of the specifics of the exchange rate system within which the interventions occur. Rather, our study encourages additional research in order to assess the extent to which our findings also describe the influence of intervention on the exchange rate spread in the context of other exchange rate systems. 


\section{References}

Andersen, Torben G. and Tim Bollerslev (1998): "Deutsche Mark-Dollar Volatility: Intraday Activity Patterns, Macroeconomic Announcements, and Longer-Run Dependencies." Journal of Finance 53, 219-265.

Andrews, Donald W.K. (1993): "Tests for Parameter Instability and Structural Change with Unknown Change Point.” Econometrica 61, 821-856.

Bhattacharya, Utpal and Paul Weller (1997): “The Advantage of Hiding One's Hand: Speculation and Central Bank Intervention in the Foreign Exchange Market." Journal of Monetary Economics 39, 251-277.

Bollerslev, Tim and Michael Melvin (1994): "Bid-Ask Spreads and Volatility in the Foreign Exchange Market: An Empirical Analysis.” Journal of International Economics 36, 355-372.

Brandner, Peter, Harald Grech and Helmut Stix (2006). "The Effectiveness of Central Bank Intervention in the EMS: The post 1993 Experience." Journal of International Money and Finance $25,580-597$.

Chari, Anusha (2007): "Heterogeneous Market-Making in Foreign Exchange Markets: Evidence from Individual Bank Responses to Central Bank Interventions." Journal of Money, Credit and Banking 39, 1137-1161.

Dacorogna, Michel M., Ulrich A. Müller, Robert J. Nagler, Richard B. Olsen and Olivier V. Pictet (1993): "A Geographical Model for the Daily and Weekly Seasonal Volatility in the Foreign Exchange Market.” Journal of International Money and Finance 12, 413-438.

Danielsson, Jon and Richard Payne (2002). "Real Trading Patterns and Prices in Spot Foreign Exchange Markets.” Journal of International Money and Finance 21, 203-222.

Danmarks Nationalbank (2003): "Monetary Policy of Denmark." Second Edition, Danmarks Nationalbank, Copenhagen.

Edison, Hali J. (1993). "The Effectiveness of Central Bank Intervention: A Survey of the Literature after 1982”, Special Papers in International Economics 18, Princeton University.

European Central Bank (2004): "The Monetary Policy of the ECB." European Central Bank, Frankfurt.

Fatum, Rasmus and Michael King (2005): "The Effectiveness of Official Foreign Exchange Intervention in a Small Open Economy: The Case of the Canadian Dollar." Bank of Canada Working Paper No. 05-21.

Fatum, Rasmus and Jesper Pedersen (2009): "Real-Time Effects of Central Bank Intervention in the Euro-Market.” Journal of International Economics 78, 11-20.

Fischer, Andreas M. and Mathias Zurlinden (1999): "Exchange Rate Effects of Central Bank Interventions: An Analysis of Transaction Prices.” Economic Journal 109, 662-676. 
Gallant, R.A. (1981): "On the bias in flexible functional forms and essentially unbiased form: The Fourier flexible form." Journal of Econometrics 15, 211-245.

Ghosh, Atish R. (2002): "Central Bank Secrecy in the Foreign Exchange Market." European Economic Review 46, 253-272.

Humpage, Owen (1999). "U.S. Intervention: Assessing the Probability of Success." Journal of Money, Credit and Banking 31, 731-747.

Humpage, Owen (2003): "Government Intervention in the Foreign Exchange Market." Federal Reserve Bank of Cleveland Working Paper No. 03-15.

Hung, Juann H. (1997). "Intervention Strategies and Exchange Rate Volatility: A Noise Trading Perspective.” Journal of International Money and Finance 16, 779-793.

Ito, Takatoshi and Tomoyoshi Yabu (2007). "What Promotes Japan to Intervene in the Forex Market? A New Approach to a Reaction Function." Journal of International Money and Finance 26, 193-212.

Melvin, Michael; Lukas Menkhoff and Maik Schmeling (2009): "Exchange Rate Management in Emerging Markets: Intervention via an Electronic Limit Order Book." Journal of International Economics 79, 54-63.

Menkhoff, Lukas (2010): "High-frequency analysis of foreign exchange interventions: What do we learn?" Journal of Economic Surveys 24, 85-112.

Mussa, Michael (1981): “The Role of Official Intervention.” Group of Thirty, New York.

Naranjo, Andy and Mahen Nimalendran (2000): "Government Intervention and Adverse Selection Costs in Foreign Exchange Markets." Review of Financial Studies 13, 453-477.

Neely, Christopher J. (2001): "The Practice of Central Bank Intervention: Looking under the Hood." Federal Reserve Bank of St. Louis Review 83, 1-10.

Neely, Christopher J. (2005): “An Analysis of Recent Studies of the Effect of Foreign Exchange Intervention.” Federal Reserve Bank of St. Louis Review 87, 685-717.

Neely, Christopher J. (2008): “Central Bank Authorities' Beliefs about Foreign Exchange Intervention.” Journal of International Money and Finance 27, 1-25.

Pasquariello, Paolo (2007): "Informative Trading or Just Costly Noise? An Analysis of Central Bank Interventions.” Journal of Financial Markets 10, 107-143.

Sarno, Lucio and Mark P. Taylor (2001): "Official Intervention in the Foreign Exchange Market: Is It Effective and, If So, How Does It Work?" Journal of Economic Literature 39, 839-868. 
Figure 1

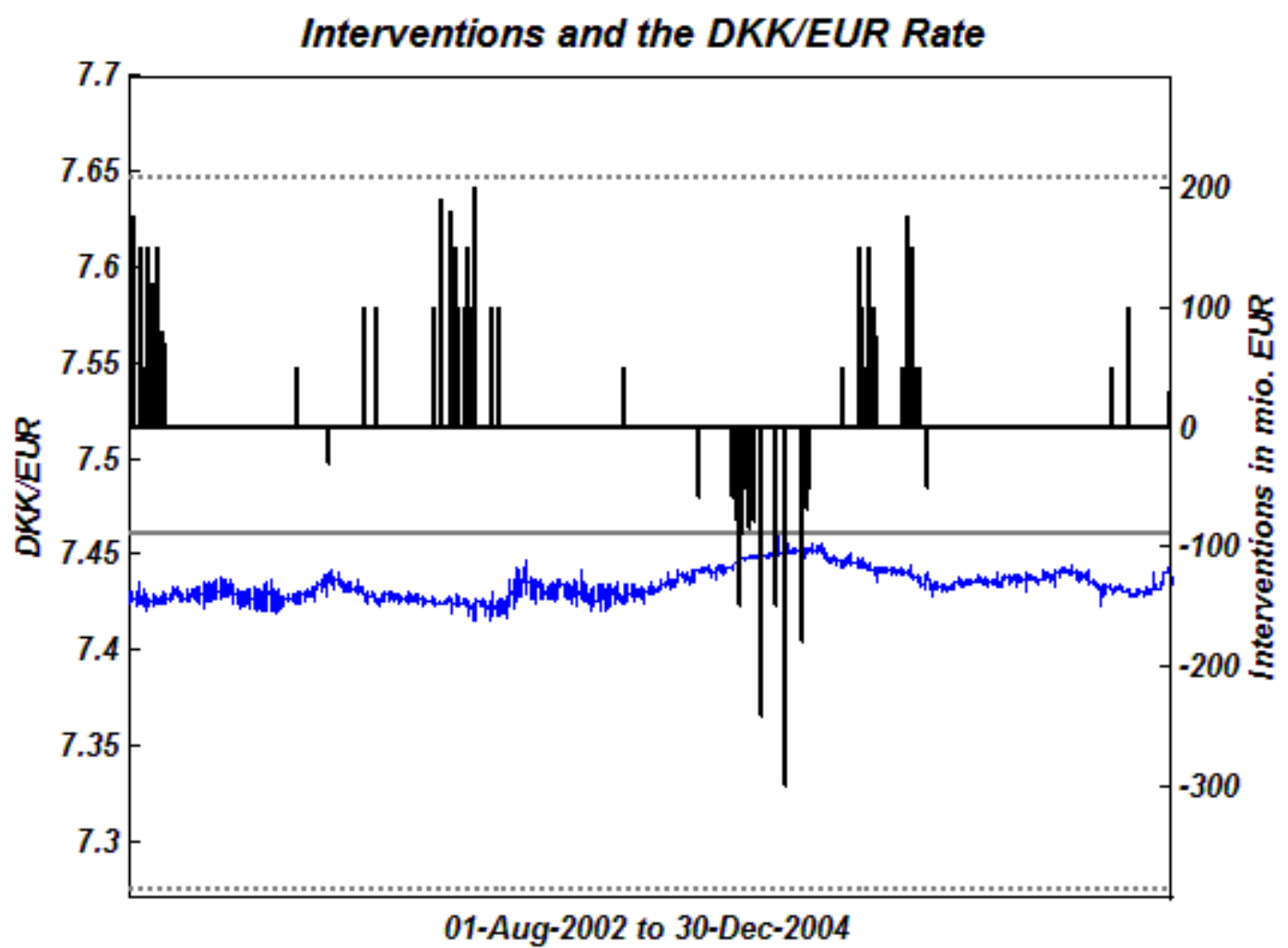

Notes:

a) Data Sources: Danmarks Nationalbank (interventions) and Olsen and Associates (exchange rates)

b) A positive intervention is a purchase of EUR against a sale of DKK; a negative intervention is a sale of EUR against a purchase of DKK; the interventions are plotted against the central parity of 7.46038 DKK/EUR

c) The exchange rate is the $5 \mathrm{~min}$. spot exchange rate; the upper and lower lines are the ERM II deviation bands 
Figure 2

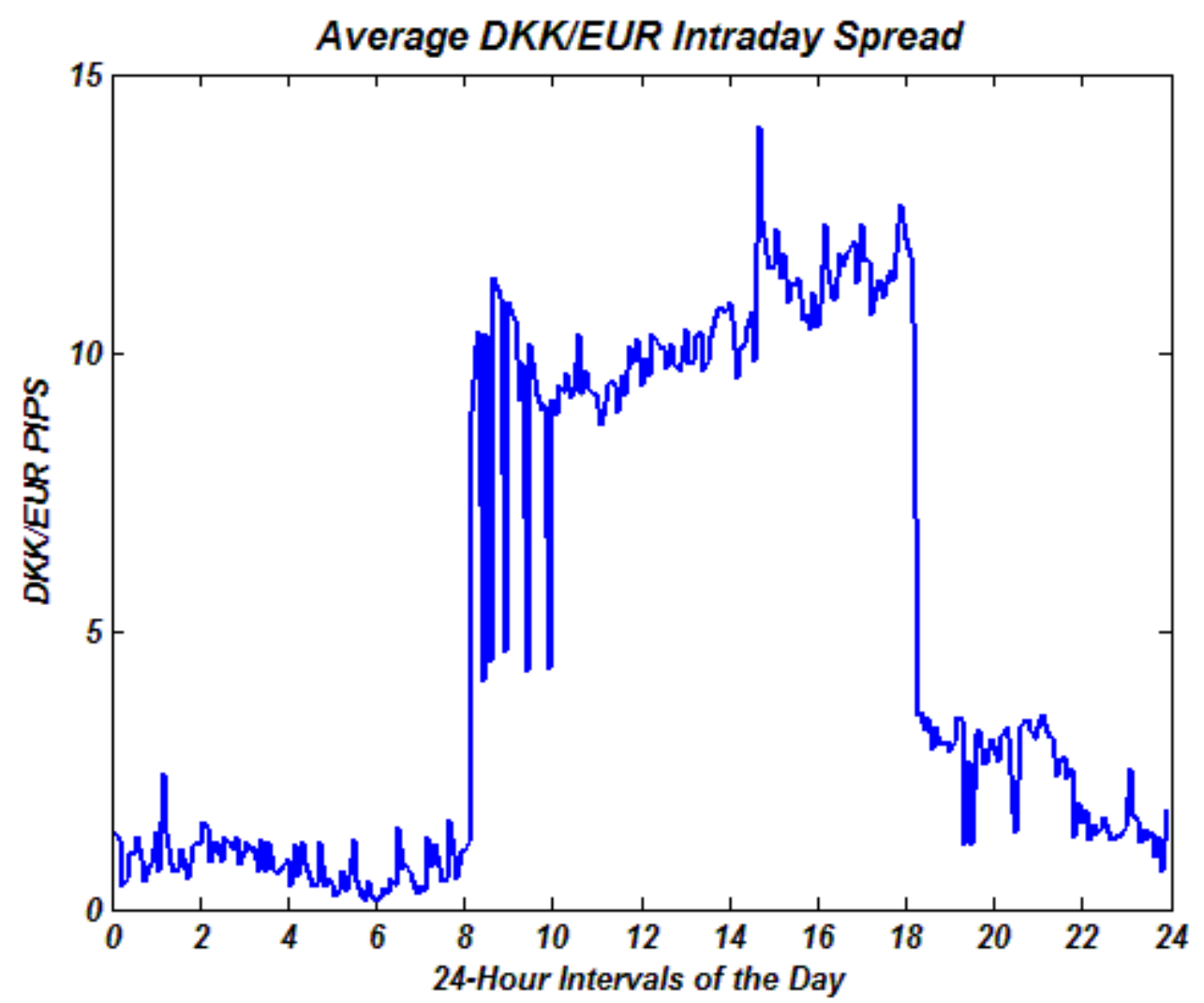

Notes:

a) Data Source: Olsen and Associates and own calculations

b) The spread is defined as bid minus ask price and measured in PIPS

c) PIPS are defined as 0.01DKK per 100EUR 


\begin{tabular}{|l|c|c|}
\hline \multicolumn{2}{|c|}{ Intervention Summary Statistics } \\
\hline & $\begin{array}{c}\text { Number of } \\
\text { Interventions }\end{array}$ & $\begin{array}{c}\text { Average amount } \\
\text { (mill. EUR) }\end{array}$ \\
\hline Daily interventions & 73 & 155 \\
\hline All & 52 & 144 \\
\hline Purchases of EUR/Sales of DKK & 21 & 182 \\
\hline Sales of EUR/Purchases of DKK & 162 & 70 \\
\hline Intraday interventions & 99 & 76 \\
\hline All & 63 & 61 \\
\hline Purchases of EUR/Sales of DKK & \\
\hline Sales of EUR/Purchases of DKK & \multicolumn{2}{|}{} \\
\hline $\begin{array}{l}\text { NOTES: } \\
\text { Data source: Danmarks Nationalbank } \\
\text { Sample period: 1 August 2002 to 31 December 2004 }\end{array}$ \\
\hline
\end{tabular}

\begin{tabular}{|c|c|c|c|}
\hline \multicolumn{4}{|c|}{ TABLE 1B Summary Statistics for 5 Minute DKK/EUR Exchange Rate Spread } \\
\hline Mean & Std. Dev. & Skewness & Kurtosis \\
\hline $\begin{array}{c}2.1 \\
(\sim 0.1)\end{array}$ & $\begin{array}{l}3.4 \\
(-)\end{array}$ & $\begin{array}{c}2.7586 \\
(0.0097) \\
\end{array}$ & $\begin{array}{c}10.4709 * * \\
(0.0193)\end{array}$ \\
\hline Minimum & Maximum & $\begin{array}{l}\text { BJ-test for } \\
\text { normality }\end{array}$ & LB Q-test (5-day lag) \\
\hline 0 & 31.0 & $\begin{array}{c}231372 * * * * \\
{[5.9915]}\end{array}$ & $\begin{array}{c}138172 * * * * \\
{[3.8415]}\end{array}$ \\
\hline \multicolumn{4}{|c|}{$\begin{array}{l}\text { NOTES: } \\
\text { Data source: Olsen and Associates } \\
\text { Sample period: } 1 \text { August } 2002 \text { to } 31 \text { December } 2004 \\
\text { The data consists of } 64383 \text { observations of DKK/EUR exchange rate bid- and ask } \\
\text { prices } \\
\text { The exchange rate spreads are calculated as ask minus bid prices and measured in } \\
\text { PIPS } \\
\text { PIPS are defined as } 0.01 D K K \text { per } 100 \text { EUR } \\
\text { * Denotes significance at } 90 \%, * * \text { denotes significance at } 95 \% \text {, *** denotes } \\
\text { significance at } 99 \% \\
\text { Standard Errors in ( ) below the point estimates; critical values in [ ] }\end{array}$} \\
\hline
\end{tabular}




\begin{tabular}{|c|c|c|}
\hline \multirow[t]{2}{*}{ TABLE 2} & \multicolumn{2}{|c|}{ xchange Rate Spread Responses to Intervention } \\
\hline & All Interventions & $\begin{array}{l}\text { Separate Intervention Purchases } \\
\text { and Sales }\end{array}$ \\
\hline \multicolumn{3}{|l|}{ Constant (e-5) } \\
\hline$\beta(0)$ & $\begin{array}{l}0.002 * * * \\
(0.0001)\end{array}$ & $\begin{array}{l}0.002 * * * \\
(0.0001)\end{array}$ \\
\hline \multicolumn{3}{|l|}{ Interventions (e-5) } \\
\hline$\gamma(0)$ & $\begin{array}{c}1.93 \\
(1.76)\end{array}$ & - \\
\hline \multicolumn{3}{|c|}{ Intervention Sales of EUR/Purchases of DKK (e-5) } \\
\hline$\gamma_{S}(0)$ & - & $\begin{array}{c}-2.30 * * \\
(1.07)\end{array}$ \\
\hline \multicolumn{3}{|c|}{ Intervention Purchases of EUR/Sales of DKK (e-5) } \\
\hline$\gamma_{P}(0)$ & - & $\begin{array}{l}4.92 * \\
(2.63)\end{array}$ \\
\hline \multicolumn{3}{|l|}{ Lags of FX-spreads } \\
\hline$\beta(1)$ & $\begin{aligned} 0.34 * * * \\
(0.010)\end{aligned}$ & $\begin{array}{r}0.34 * * * \\
(0.009)\end{array}$ \\
\hline$\beta(2)$ & $\begin{array}{r}0.20 * * * \\
(0.008) \\
\end{array}$ & $\begin{array}{r}0.20^{* * * *} \\
(0.008) \\
\end{array}$ \\
\hline$\beta(3)$ & $\begin{aligned} 0.12 * * * \\
(0.008)\end{aligned}$ & $\begin{array}{r}0.12 * * * \\
(0.008)\end{array}$ \\
\hline$\beta(4)$ & $\begin{array}{r}0.09 * * * \\
(0.008)\end{array}$ & $\begin{array}{r}0.09 * * * \\
(0.008)\end{array}$ \\
\hline$\beta(5)$ & $\begin{array}{r}0.07 * * * \\
(0.009)\end{array}$ & $\begin{array}{r}0.07 * * * \\
(0.009)\end{array}$ \\
\hline$\beta(6)$ & $\begin{array}{l}0.08 * * * \\
(0.007)\end{array}$ & $\begin{array}{l}0.08^{* * * *} \\
(0.007)\end{array}$ \\
\hline$\overline{\mathrm{R}^{2}}$ & 0.60 & 0.60 \\
\hline \#Interventions & 162 & - \\
\hline $\begin{array}{l}\text { \#Intervention Sales } \\
\text { of EUR }\end{array}$ & - & 63 \\
\hline $\begin{array}{l}\text { \#Interventions } \\
\text { Purchases of EUR }\end{array}$ & - & 99 \\
\hline \multicolumn{3}{|c|}{$\begin{array}{l}\text { NOTES: } \\
\text { (a) * Denotes significance at } 90 \%, * * \text { denotes significance at } 95 \%, * * * \text { denotes } \\
\text { significance at } 99 \% \\
\text { (b) Standard Errors in ( ) below the point estimates; lags in ( ) in Variable Name } \\
\text { (c) Estimations are carried out using OLS with heteroskedasticity and } \\
\text { autocorrelation consistent (HAC) standard errors and covariances } \\
\text { (d) Column } 1 \text { displays the estimation results pertaining to Equation (1) in the } \\
\text { text; column } 2 \text { displays the estimation results pertaining to Equation (2) in the text } \\
\text { (e) The dependent variable is the DKK/EUR exchange rate spread } \\
\text { (f) The independent variables are contemporaneous intervention, and lags of the } \\
\text { dependent variable }\end{array}$} \\
\hline
\end{tabular}




\begin{tabular}{|c|c|c|}
\hline \multirow[t]{2}{*}{ TABLE 3} & \multicolumn{2}{|c|}{$\begin{array}{l}\text { Exchange Rate Spread Responses to Intervention: } \\
\text { WLS Conditional Mean Equation }\end{array}$} \\
\hline & All Interventions & $\begin{array}{c}\text { Separate Intervention Purchases } \\
\text { and Sales }\end{array}$ \\
\hline \multicolumn{3}{|l|}{ Constant (e-5) } \\
\hline$\beta(0)$ & $\begin{array}{l}0.002 * * * \\
(0.0001)\end{array}$ & $\begin{array}{l}0.002 * * * \\
(0.0001)\end{array}$ \\
\hline \multicolumn{3}{|l|}{ Interventions (e-5) } \\
\hline$\gamma(0)$ & $\begin{array}{c}0.81 \\
(1.28)\end{array}$ & - \\
\hline \multicolumn{3}{|c|}{ Intervention Sales of EUR/Purchases of DKK (e-5) } \\
\hline$\gamma_{S}(0)$ & - & $\begin{array}{c}-2.59 * * \\
(1.22)\end{array}$ \\
\hline \multicolumn{3}{|c|}{ Intervention Purchases of EUR/Sales of DKK (e-5) } \\
\hline$\gamma_{P}(0)$ & - & $\begin{array}{l}4.35 * * \\
(2.18)\end{array}$ \\
\hline \multicolumn{3}{|l|}{ Lags of FX-spreads } \\
\hline$\beta(1)$ & $\begin{array}{r}0.33^{* * * *} \\
(0.008)\end{array}$ & $\begin{array}{r}0.34 * * * \\
(0.009)\end{array}$ \\
\hline$\beta(2)$ & $\begin{array}{r}0.19 * * * \\
(0.007)\end{array}$ & $\begin{array}{r}0.20 * * * \\
(0.008)\end{array}$ \\
\hline$\beta(3)$ & $\begin{array}{r}0.12 * * * \\
(0.007)\end{array}$ & $\begin{array}{r}0.12 * * * * \\
(0.008)\end{array}$ \\
\hline$\beta(4)$ & $\begin{array}{r}0.10^{* * * *} \\
(0.007)\end{array}$ & $\begin{array}{r}0.09 * * * \\
(0.008)\end{array}$ \\
\hline$\beta(5)$ & $\begin{array}{r}0.07 * * * \\
(0.007)\end{array}$ & $\begin{array}{r}0.06^{* * * *} \\
(0.008)\end{array}$ \\
\hline$\beta(6)$ & $\begin{array}{c}0.08 * * * \\
(0.006)\end{array}$ & $\begin{array}{c}0.08^{* * * *} \\
(0.007)\end{array}$ \\
\hline \#Interventions & 162 & - \\
\hline $\begin{array}{l}\text { \#Intervention Sales } \\
\text { of EUR }\end{array}$ & 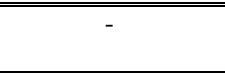 & 63 \\
\hline $\begin{array}{l}\text { \#Interventions } \\
\text { Purchases of EUR }\end{array}$ & 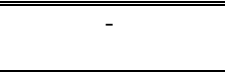 & 99 \\
\hline \multicolumn{3}{|c|}{$\begin{array}{l}\text { NOTES: } \\
\text { (a) * Denotes significance at } 90 \%, * * \text { denotes significance at } 95 \%, * * * \text { denotes } \\
\text { significance at } 99 \% \\
\text { (b) Standard Errors in ( ) below the point estimates; lags in ( ) in Variable Name } \\
\text { (c) Estimations are defined in Equation (2) in the text, and carried out using } \\
\text { WLS } \\
\text { (d) Column } 1 \text { displays the estimation results of the conditional mean model } \\
\text { defined in Equation (1) in the text; column } 2 \text { displays the estimation results of the } \\
\text { conditional mean model defined in Equation (2) in the text } \\
\text { (e) The dependent variable is the DKK/EUR exchange rate spread } \\
\text { (f) The independent variables are contemporaneous intervention, and lags of the } \\
\text { dependent variable } \\
\text { (g) } \mathrm{R}^{2} \text { is not applicable to the WLS estimation procedure }\end{array}$} \\
\hline
\end{tabular}




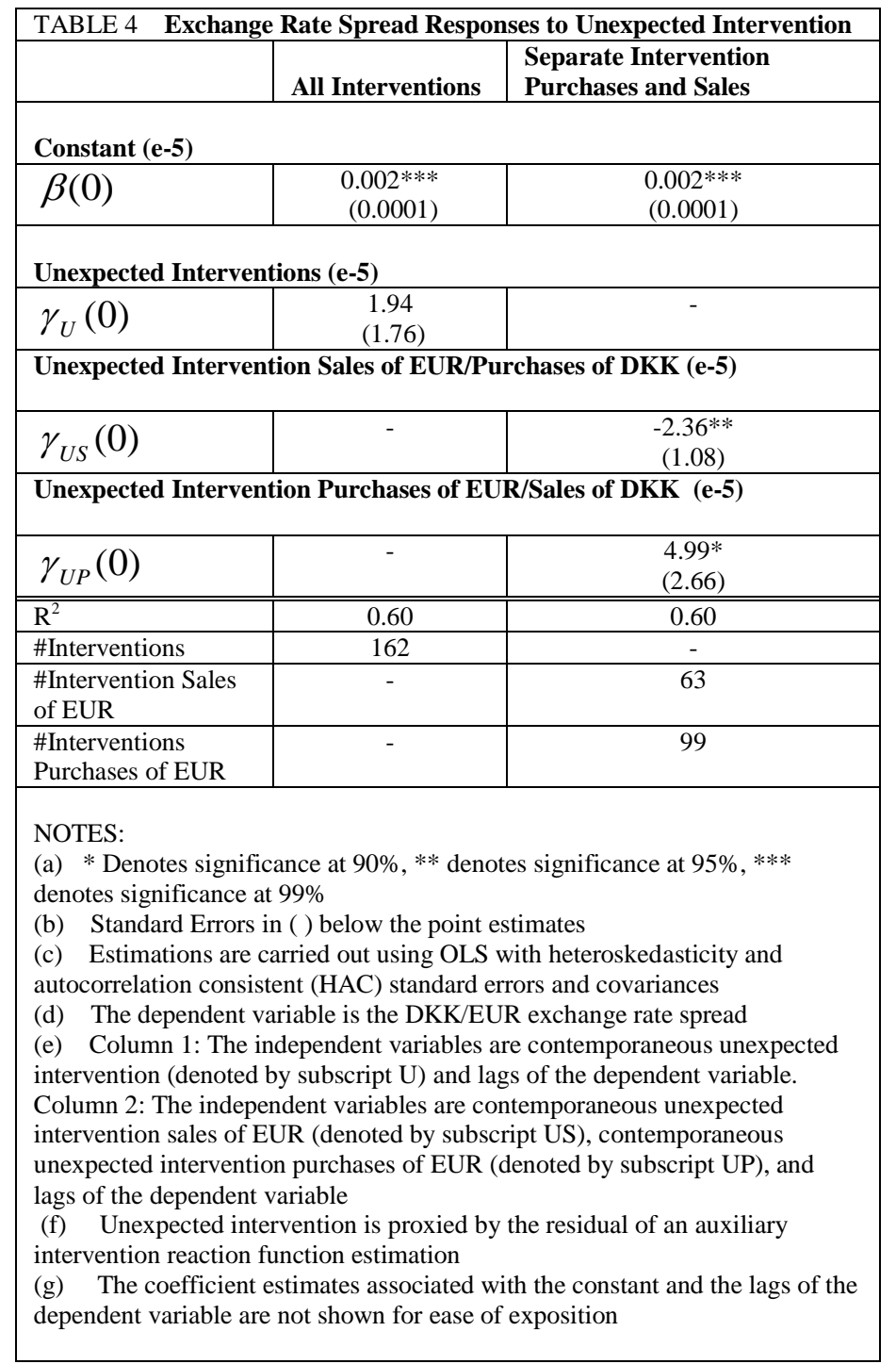




\begin{tabular}{|c|c|c|}
\hline \multicolumn{3}{|c|}{$\begin{array}{l}\text { Exchange Rate Spread Responses to Intervention } \\
\text { and Macro News }\end{array}$} \\
\hline & All Interventions & $\begin{array}{c}\text { Separate Intervention } \\
\text { Purchases and Sales }\end{array}$ \\
\hline \multicolumn{3}{|c|}{ Standardized Intervention All } \\
\hline$\gamma_{S D}(0)$ & $\begin{array}{c}0.0017 \\
(0.0016)\end{array}$ & - \\
\hline \multicolumn{3}{|c|}{ Standardized Intervention Sales of EUR/Purchases of DKK } \\
\hline$\gamma_{S D S}(0)$ & - & $\begin{array}{c}-0.0016^{* *} \\
(0.0007)\end{array}$ \\
\hline \multicolumn{3}{|c|}{ Standardized Intervention Purchases of EUR/Sales of DKK } \\
\hline$\gamma_{S D P}(0)$ & - & $\begin{array}{l}0.0022 * \\
(0.0012)\end{array}$ \\
\hline \multicolumn{3}{|c|}{ Standardized Danish Macro News } \\
\hline DKUNEMP(0) & $\begin{array}{l}0.0108^{*} \\
(0.0060)\end{array}$ & $\begin{array}{l}0.0108^{*} \\
(0.0060)\end{array}$ \\
\hline DKUNEMP(1) & $\begin{array}{c}0.00102^{*} \\
(0.0044) \\
\end{array}$ & $\begin{array}{l}0.0102 * * \\
(0.0044)\end{array}$ \\
\hline $\operatorname{DKTB}(0)$ & $\begin{array}{r}0.0045 \\
(0.0041) \\
\end{array}$ & $\begin{array}{c}0.0045 \\
(0.0041) \\
\end{array}$ \\
\hline $\operatorname{DKTB}(1)$ & $\begin{array}{c}-0.0035^{* *} \\
(0.0021) \\
\end{array}$ & $\begin{array}{c}-0.0035^{* *} \\
(0.0021) \\
\end{array}$ \\
\hline $\operatorname{DKCA}(0)$ & $\begin{array}{c}-0.0112 * * * \\
(0.0035)\end{array}$ & $\begin{array}{c}-0.0112 * * * \\
(0.0035)\end{array}$ \\
\hline $\mathrm{DKCA}(1)$ & $\begin{array}{l}-0.0044 \\
(0.0043)\end{array}$ & $\begin{array}{l}-0.0044 \\
(0.0043)\end{array}$ \\
\hline $\operatorname{DKCPI}(0)$ & $\begin{array}{c}0.0138 \\
(0.0150)\end{array}$ & $\begin{array}{c}0.0138 \\
(0.0150)\end{array}$ \\
\hline DKCPI(1) & $\begin{array}{l}-0.0048 \\
(0.0078)\end{array}$ & $\begin{array}{l}-0.0048 \\
(0.0078)\end{array}$ \\
\hline DKGDP(0) & $\begin{array}{l}-0.0085 \\
(0.0099)\end{array}$ & $\begin{array}{l}-0.0085 \\
(0.0099) \\
\end{array}$ \\
\hline DKGDP(1) & $\begin{array}{c}-0.0274 * * * \\
(0.0054) \\
\end{array}$ & $\begin{array}{c}-0.0274 * * * \\
(0.0054) \\
\end{array}$ \\
\hline $\mathrm{DKCC}(0)$ & $\begin{array}{l}0.0120^{* * *} \\
(0.0049)\end{array}$ & $\begin{array}{c}0.0120 * * \\
(0.0049)\end{array}$ \\
\hline $\mathrm{DKCC}(1)$ & $\begin{array}{c}-0.0065^{* *} \\
(0.0029) \\
\end{array}$ & $\begin{array}{c}-0.0065^{* *} \\
(0.0029) \\
\end{array}$ \\
\hline \multicolumn{3}{|c|}{ Standardized German Macro News } \\
\hline $\mathrm{DEIFO}(0)$ & $\begin{array}{c}-0.0101 * * * \\
(0.0038)\end{array}$ & $\begin{array}{c}-0.0101 * * * \\
(0.0038)\end{array}$ \\
\hline $\mathrm{DEIFO}(1)$ & $\begin{array}{c}0.0018 \\
(0.0045) \\
\end{array}$ & $\begin{array}{c}0.0018 \\
(0.0045) \\
\end{array}$ \\
\hline DEGDP(0) & $\begin{array}{c}-0.0155 * * * \\
(0.0026)\end{array}$ & $\begin{array}{c}-0.0155^{* * *} * \\
(0.0026)\end{array}$ \\
\hline DEGDP(1) & $\begin{array}{c}-0.0057 * * * \\
(0.0020) \\
\end{array}$ & $\begin{array}{c}-0.0057 * * * \\
(0.0020) \\
\end{array}$ \\
\hline $\operatorname{DEIP}(0)$ & $\begin{array}{c}0.0035 \\
(0.0033)\end{array}$ & $\begin{array}{c}0.0035 \\
(0.0033)\end{array}$ \\
\hline DEIP(1) & $\begin{array}{c}0.0070 \\
(0.0075) \\
\end{array}$ & $\begin{array}{c}0.0070 \\
(0.0075) \\
\end{array}$ \\
\hline \multicolumn{3}{|c|}{ Standardized Euro-Area Macro News } \\
\hline EACPI $(0)$ & $\begin{array}{c}-0.0053 \\
(0.0058) \\
\end{array}$ & $\begin{array}{c}-0.0053 \\
(0.0058) \\
\end{array}$ \\
\hline EACPI(1) & $\begin{array}{c}0.0044 \\
(0.0033)\end{array}$ & $\begin{array}{c}0.0044 \\
(0.0033) \\
\end{array}$ \\
\hline $\mathrm{EAIP}(0)$ & $\begin{array}{c}0.0029 \\
(0.0031) \\
\end{array}$ & $\begin{array}{c}0.0029 \\
(0.0031) \\
\end{array}$ \\
\hline EAIP(1) & $\begin{array}{c}-0.0023 \\
(0.0023)\end{array}$ & $\begin{array}{c}-0.0023 \\
(0.0023) \\
\end{array}$ \\
\hline $\mathrm{EABC}(0)$ & -0.0355 & -0.0355 \\
\hline
\end{tabular}




\begin{tabular}{|l|c|c|}
\hline EABC(1) & $(0.0242)$ & $(0.0243)$ \\
\hline \hline $\mathrm{R}^{2}$ & $\begin{array}{c}0.0134 \\
(0.0098)\end{array}$ & $\begin{array}{c}0.0134 \\
(0.0098)\end{array}$ \\
\hline \hline \#Interventions & 0.60 & 0.60 \\
\hline \hline \#Intervention Sales of & 162 & - \\
EUR & - & 63 \\
\hline \hline \#Interventions & - & 99 \\
Purchases of EUR & - & \\
\hline
\end{tabular}

NOTES:

(a) * Denotes significance at $90 \%$, ** denotes significance at $95 \%$, *** denotes significance at $99 \%$

(b) Standard Errors in ( ) below the point estimates; lags in ( ) in Variable Names

(c) Estimations are carried out using OLS with heteroskedasticity and autocorrelation consistent (HAC) standard errors and covariances

(d) The dependent variable is the DKK/EUR exchange rate spread.

(e) The independent variables are contemporaneous standardized intervention sales of EUR (denoted by subscript SDS), contemporaneous standardized intervention purchases of EUR (denoted by subscript SDP), contemporaneous and lagged standardized macro news, and lags of the dependent variable

(f) Macro news variables capture news surprises as the difference between actual announcement and survey expectations extracted from Bloomberg. The estimations take into account news regarding Danish Unemployment

(DKUNEMP), Trade Balance (DKTB), Current Account (DKCA), CPI

(DKCPI), GDP (DKGDP), and Consumer Confidence (DKCC); German IFO Index (DEIFO), GDP (DEGDP), and Industrial Production (DEIP); Euro-Area CPI (EACPI), Industrial Production (EAIP), and Business Climate Index (EABC).

(g) All variables are standardized by dividing each variable by its respective sample standard deviation

(h) The coefficient estimates associated with the constant and the lags of the dependent variable not shown for ease of exposition 